\title{
Problem BASED LEARNING: BARROW AND BLOOM TAXONOMY (Experimental activity)
}

\author{
Yolanda Marina Vargas-Rodríguez*, Adolfo Eduardo Obaya \\ Valdivia, Guadalupe Ivteh Vargas Rodríguez \\ FES CUAUTITLAN UNAM. \\ Fisicoquímica. Depto Ciencias Químicas, México
}

\begin{abstract}
This paper explains what the PBL consists of, exposes the role of the teacher and the student in this methodology, and discusses the convenience of using pictograms to determine the convenience of raising in the PBL, problems, or cases. Based on our teaching experience, a taxonomy is proposed to facilitate an awareness of these differences and help teachers choose a problem-based learning method more appropriate for their students. Also, a PBL planning process is presented for an experimental activity and its process evaluation.
\end{abstract}

\section{KEYWORDS}

PBL, Taxonomy, Pictograms, Experimental Activity

\section{What is PBL?}

There are currently several definitions of PBL (Problem-Based Learning), but it is generally accepted that PBL is a didactic methodology that seeks student learning through problem solving (Villalobos V. et al., 2006).

The PBL begins in the late sixties of the last century in the Faculty of Health Sciences of Mc Master's University, in Canada (Servant-Miklosa, 2019). The aim of the University was to improve the education of medical students since the mode of teaching consisted of an accumulation of topics and presentations by teachers. Eventually, all schools of medicine, nursing, pharmacy, and related careers adopted this methodology to a lesser or greater extent (Barrows \& Tamblyn, 1980; Barrows, 1996).

In introducing PBL, it was sought that students learn with real-life problems, where other disciplines that could help solve, problems were included (Kyung-Hee, 2018). This methodology brought good results, so much so that it began to be implemented not only with medical students but in other professional careers, in upper secondary, higher, and postgraduate education.

In PBL it can be used as a methodological strategy during the teaching process, or as a didactic tool for different subjects. From this perspective, PBL can be defined as a learning methodology based on real-life problems; in which the protagonist is focused on the student and not on the teacher (Torp \& Sarge, 1999). 
We work with teams of students who meet to solve a problem selected or specially designed for the achievement of learning objectives, with the support of a teacher, who has the role of tutor (Sola et al, 2006).

It is important to mention and consider that PBL is a methodology that provides a better alternative to be moving in the right way when the learning objectives are well defined (Amol et al, 2020). Barrows (1986) defines PBL as a learning method based on the principle of using problems as a starting point for the acquisition of new knowledge, problem solving is used as a basis for achieving learning objectives and developing competences and skills transferable to professional practice. These problems are characterized by their originality, by having missing data or pieces that the student must discover, search, and find; they are partially defined and divergent, that is, they do not have a single correct solution. Therefore, in this PBL methodology changes the role of the student, from a passive receiver to an active, responsible, and autonomous role and changes the role of the teacher, from transmitter of knowledge, to guide, who provides the support and appropriate help to achieve the learning objectives.

The PBL is based on different theoretical currents on human learning. (Matus et al., 2005). Learning is conceived as a construction that is achieved thanks to the interaction of individual and social factors. Individual factors operate when the student relates concepts to learning and gives them meaning through the cognitive structure they possess (Díaz Barriga, F. and Hernández G., 2002) The exchange of information between teammates who have different levels of knowledge, as well as social interaction, promotes a modification of students' schemes by creating cognitive conflicts. With this look of educational approach, the teacher creates the optimal conditions for the student to carry out a constructive activity, as well as to guide said activity so that the student achieves a scaffolding to what the contents mean and represent. That is why it is not the most important the final product that the students obtain, but the process that leads them to give a certain answer; whereas the teacher should be interested in how the knowledge that is already possessed is being rebalanced from the new information that the student receives (Correa et al., 2002).

\subsection{Teacher-Facilitator at PBL}

In PBL, the teacher assumes the role of facilitator rather than lecturer. The facilitator helps groups build understanding and connect concepts through scaffolding information, lead exploration, reinforce understanding of difficult concepts, and introduce resources. In addition, the facilitator encourages reflection on the group process and the results of the group. The facilitator may also be considered a coach or guide who provides feedback and encouragement (Salari, et. al. 2018). Then, depending on the PBL methods described below, the teacher can direct learning completely (dark box), or partially (half dark and half white box) (Barrows, 1986), as shown in Figure 1.

\subsection{Role of the student}

PBL is a teaching method that substantially increases student motivation, since its dynamics make students active subjects of the teaching and learning process (Amol, 2020). The student is the center of this process and to work with this method requires the teamwork of students. (Williams, 2016). Emphasizing that students inquire and intervene in their environment and build meaningful learning for themselves (Obaya, Vargas and Delgadillo, 2011).

Then, depending on the method, learning can be partially directed by the students or directed entirely by the student. In PBL students are constantly involved in the acquisition of their knowledge through inquiry and review. That is, students take responsibility for their learning, 
identify what they need to know to solve the problem. It is a methodology that stimulates selflearning and allows the student's practice when facing real situations and identifying their knowledge deficiencies. Students can observe their progress in the development of knowledge and skills, becoming aware of their own development (Torp, L and Sarge, S., 1999).

\subsection{Cases or Problems}

PBL requires the elaboration and presentation of real situations or cases (cases) that are represented by a dark circle or simulated in a complete simulation of the problem represented as a white or partial circle of the problem, or a partial simulation of the problem, shown with the pictogram of a circle, half dark and half white (Figure 1). It is worth mentioning that, in each of these situations, learning is directed by the teacher (dark box), learning is directed by the student or partially directed by both. (Half dark and half white painting) (Barrow, 1986). To describe PBL as a teaching methodology, the pictograms of the variables that describe it are presented

\begin{tabular}{l|l}
\hline PICTOGRAM & VARIABLES IN TEACHING IN MEDICINE \\
\hline & Full case \\
\hline & Partial simulation of the problem \\
\hline & Complete simulation of the problem \\
\hline & Student-led learning \\
\hline & \begin{tabular}{l} 
Partially student- and teacher-led \\
\hline
\end{tabular} \\
\hline
\end{tabular}

Figure 1. Pictograms for the direction of learning. Taken from Barrows, 1986.

\subsection{Taxonomy of PBL}

It can have many different meanings depending on the design of the educational method employed and the skills of the teacher. The many possible variables can produce wide variations in the quality and educational objectives that can be achieved. In analogy with Barrow (1986), which describes the goals in medical education, the most important goals of PBL for application in chemistry are:

1. Structuring of knowledge for use in chemical contexts (SKUCC ECCQ). To facilitate the subsequent retrieval and application of information, both from the chemical sciences and to future chemical work, learning must occur in contexts of application in the professional area. Education is most effective when carried out in the context of future tasks (Kyung-Hee, 2018).

2. The development of an effective chemical reasoning process (DECRPDPRQ). With proper design, PBL can present simulations of problems that allow this to occur (Barrows \& Tamblyn 1980; Stentoft, 2019) 
3. The development of self-directed learning skills (DSLS DHAA). Self-assessment and self-directed learning skills allow the student to become sensitive to personal learning needs and locate and use appropriate information resources.

4. Increased motivation to learn (IML MMA). Motivation improves student learning.

\subsection{Methods in PBL}

Lecture-Based Case Method: The teacher presents students with information at lectures and then a case or two. Some generation of hypotheses, data analysis, and limited decision-making may be required. Without research or case-making skills, applying this method achieves an SKUCC: I, DECRP:0, DSLS:1, IML:1.

Case-Based Lectures: Students are presented with more complete cases prior to the lecture. The cases highlight the material to be covered. Studentsmust analyze the case using their previous knowledge before new knowledge is provided. This effort should lead to a chemically oriented structuring of the subsequent information provided at the conference, as opposed to a possible restructuring of the information. already provided, as may occur in the previous class demonstration method. There is no self-directed learning, unless out of curiosity the student seeks some resources to better understand the cases. However, it has a greater structuring of knowledge for use in chemical contexts, development of an effective chemical reasoning process and greater motivation to learn, going from 1 to 2, as seen in Figure 2, the SKUCC: 1, DECRP: 2, DSLS: 0, IML 2.

Case Method: Students receive a complete case study and research in preparation for further discussion in class. This gives DSLS a strong, but not complete, score. The subsequent interactive discussion of the case in class, facilitated by the teacher, in a tutorial, combines student-led and teacher-led learning. This is a stronger challenge for hypothesis generation, data analysis and decision-making with a more active structuring of information in a clinical context. It's a more motivating method. With the following taxonomic levels; SKUCC: 3, DECRP: 3, DSLS: 3, IML: 4.

Based on Modified Cases: This method is used in small tutorial groups. More elements of the SKUCC are challenged than in previous methods, as students also decide on research actions. Skill in self-directed learning is a goal and the use of this method is designed to address DHAA directly. In addition, both DPRQ and DSLS are not fully addressed because students are not required to actively apply learning outcomes such as problem reasoning again. Greater chemical structuring occurs in memory by combining DECRP and DSLS. It is very motivating, so the taxonomic levels are higher than the previous method. SKUCC: 4, D DECRP:3, DSLS: 3, IML:5.

Problem-Based. There is an active exploration and evaluation of the problem, guided by the teacher, using facilitation or mentoring skills, which directly activate the student's previous knowledge, many of which might otherwise be beyond conscious recall, for review and association with new learning (Stentoft, 2019). More of the students' prior knowledge is activated in the design of an inquiry strategy (Amol et al, 2020) and the analysis of learning needs for, DSLS also involves this. SKUCC: 4, DECRP: 4, DSLS: 4, IML: 5.

Based on Closed-Loop Problems. This is an extension of the problem-based method described above. These steps further address SKUCC, DECRP, and DSLS, as students must go beyond acquiring and discussing new knowledge in a way that allows them to see its value and actively assess their prior knowledge and problem-solving skills. Another round of self-directed learning 
may be needed because of this second analysis and synthesis of problems. SKUCC: 5, DECRP: 5, DSLS: 5, IML: 5.

In this material it is proposed to relate the taxonomy of PBL with the Taxonomy of Bloom (Marzano \& Kendall, 2007) in the 6 levels of learning, as shown in Figure 2.

1. The first level of Knowledge (L1), is aimed at the ability to utilize memory and remember facts, processes, schemes, methods, etc., without carrying out an elaboration of the content. This level will be achieved in the conference-based case method.

2. Comprehension is the second level (L2). Here it is about students understanding and interpreting the information, expressing the ideas in their own words. Level obtained in the method of case-based transfers.

3. The third level is Application (L3). It consists of students applying the new concepts in different situations. This level can be obtained by applying the case method, modified casebased method, problem-based method, and closed-loop problem-based method.

4. The fourth level, Analysis (L4), focuses on the ability to separate the constituent elements of an information, dividing it into parts to differentiate them. This level can be obtained by applying, modified case-based method, problem-based method, and closed-loop problembased method.

5. Synthesis (L5) involves bringing the parts together to form a whole. Problems can be detected and analyzed, but not be prepared to perform a synthesis. Thus, a correct synthesis requires that a person be able to work with different data and information and build a whole creating a pattern where it did not previously exist. This level can be obtained by applying, problem-based method and in the closed-loop problem-based method.

6. Evaluation (L6) refers to the ability to make value judgments about a material (report, law, statement, essay, etc.) specific to a particular purpose. And this is based on well-defined criteria. This level can be obtained by applying the closed-loop problem-based method. 
International Journal of Education (IJE) Vol.9, No.4, December 2021

\begin{tabular}{|c|c|c|c|c|c|c|}
\hline PICTOGRAM & METHOD & $\begin{array}{l}\text { STRUCTURING } \\
\text { INFORMATION INA } \\
\text { CHEMICAL CONTEXT } \\
\text { (SICC) }\end{array}$ & $\begin{array}{l}\text { DEVELLPPMENT OFA } \\
\text { CHEMICAL REASONNG } \\
\text { PROCESS (DCRP) }\end{array}$ & $\begin{array}{l}\text { SKLLLS DEVELOPMENT OF } \\
\text { SEFF-DIRECEED LEARNNG } \\
\text { (SOSLL) }\end{array}$ & $\begin{array}{l}\text { GREATER MOTINATION } \\
\text { TOLLERN } \\
\text { (GML) }\end{array}$ & $\begin{array}{l}\text { BLOONS } \\
\text { TAXONOMY }\end{array}$ \\
\hline & $\begin{array}{l}\text { Conference-based } \\
\text { cases }\end{array}$ & 1 & 1 & 0 & 1 & L1 \\
\hline & $\begin{array}{l}\text { Case-based } \\
\text { conferences }\end{array}$ & 2 & 2 & 0 & 2 & L2 \\
\hline & Case Method & 3 & 3 & 3 & 3 & L3 \\
\hline & $\begin{array}{l}\text { Based on modified } \\
\text { cases }\end{array}$ & 4 & 3 & 3 & 5 & $L 3-L 4$ \\
\hline & Problem-based & 4 & 4 & 4 & 5 & $L 3-L 6$ \\
\hline & $\begin{array}{l}\text { Based on closed-10op } \\
\text { issues }\end{array}$ & 5 & 5 & 5 & 5 & $L 3 \cdot L 6$ \\
\hline
\end{tabular}

Figure 2. PBL methods, skills and competencies acquired, as well as learning levels of Bloom's taxonomy. Adapted from (Barrows, 1986).

\subsection{PBL Methodology}

PBL employs constructivist principles to encourage the application of prior knowledge, collaborative learning, and participation. To begin a PBL activity, a small group of students analyze a problem, identify relevant facts, and apply existing knowledge and experiences to solve a problem (Hicks, 2011). The methodology for developing PBL has three fundamental stages,

1. El planning process,

2. Process development (application) and

3. Evaluation to find out the acquired learning, skills, and competences: in the evaluation of structuring knowledge for use in chemical contexts, the development of the process of effective chemical reasoning (DECRP) and the development of self-directed learning skills, as well as in qualitative evaluation where greater motivation to learn (IML) is observed, as shown in Figure 3. 
International Journal of Education (IJE) Vol.9, No.4, December 2021

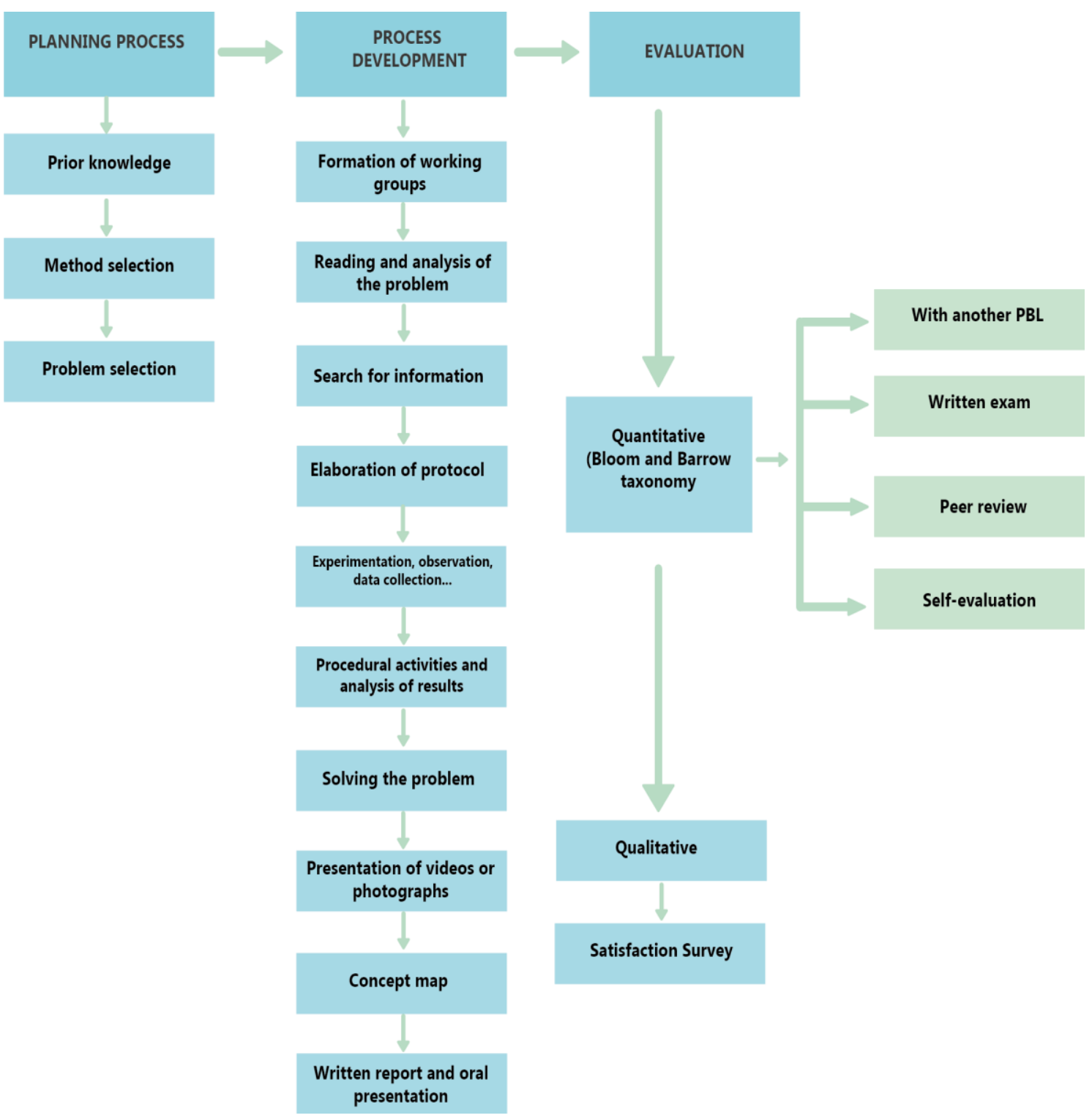

Figure 3. Stages of PBL with experimental activity. Own elaboration.

\subsection{Planning Process}

Previous knowledge: As a previous step to the planning and use of PBL, two fundamental aspects must be taken into account: That the knowledge already available to students is sufficient and that they will help them build the new learning that will be proposed in the problem and that the context and the environment favors the autonomous and team work that the students will carry out (communication with teachers, access to sources of information, sufficient spaces, etc.). Select the objectives that, framed within the competences established in the subject, and the significant learning is intended that the students achieve with the activity.

Select the case, adapt a problem, or design the problem situation on which the students will have to work. To do this, the content must:

Being complex (but not impossible) enough to be challenging for students. In this way their motivation will increase and the need to prove themselves to properly guide the task. 
Be broad enough so that students can ask questions and approach the problem with an overview, but without this breadth becoming demotivated or anxiety-reducing.

Therefore, for PBL, it is important to transform the statements of the "usual problems" that are made in the classroom, towards a possible statement that favors solving the problem as an investigation (Martínez Torregosa et al., 2005; Irazoque, 2005; Izquierdo, 2005). For example: how long does pasteurized milk decompose at room temperature? (Fernández and Aguado, 2017; Obaya, et al, 2018) In the field of Chemical, Pharmaceutical and Engineering Sciences, it is recurrent that cases or problems are solved by experimenting or through access to experimental results or the simulation of experimental results, in which we call "laboratory experiences" or "Problems with experimental activity". PBL has been used in experimental courses in the areas of chemistry, for example, in analytical chemistry (Boyce \& Singh, 2008; Hicks, \& Bevsek, 2011), in organic chemistry (Winschel, et al. 2015; Shultz \& Li, 2015; Kayala, et al. 2011) and in physical chemistry (Obaya et al, 2018; Vargas-Rodríguez, et al. 2020; Obaya et al, 2021).

\subsection{Process development}

Among the skills that are sought to develop in students because of working through the conception of problems and solutions are:

1. Abstraction: involves the representation and management of ideas and knowledge structures with greater ease and deliberation.

2. Information acquisition and management: obtain, filter, organize and analyze information from different sources.

3. Understanding of complex systems: ability to see the interrelation of things and the effect that the parts produce in the whole and the whole in the parts, in relation to natural, social, organizational, technological systems, etc.

4. Experimentation: inquisitive disposition that leads to hypotheses, to put them to the test and to evaluate the resulting data.

5. Cooperative work: flexibility, openness and positive interdependence aimed at the joint construction of knowledge.

Considering the above, the development of PBL in this guide consists of the following phases (Vargas-Rodríguez, et al., 2021).

a. $\quad$ Group of 3 to 5 members.

b. Reading and analysis of the problem statement. It is sought that students understand the statement and what is demanded. Students should make a list of those concepts that are known. It is necessary for all team members to understand the problem, therefore, the teacher must be attentive to the discussions of the groups and, if any topic in specific requires special attention, discuss it with all the groups in common.

c. Next, require teams of students to carry out collaborative activities for the search for information, which is required to make a proposal to solve the problem posed. It is worth mentioning this stage helps students to be aware of what they know and what they do not know and what information they will need to solve the problem. Teams of students can ask other questions (in PBL cycles) to arrive at the hypothesis. Students must obtain the references from where they obtain the information (books, articles, web pages, etc.).

d. Considering problems that are solved with experimental collaborative activity, students must design a research protocol that allows them to obtain experimental data. The teacher must discuss with each of the teams each of the stages of their protocol proposal. 
e. Collaboratively perform the experimental part necessary to solve the problem and obtain the experimental data. It is important that students take photographs and / or videos of the experimental part.

f. In the next stage, students should review procedural collaborative activities with the aim of solving the problem posed, and that each group of students discuss the resolution of this in PBL cycles that may arise. It is recommended that the teacher guide students in the processing of experimental data, when necessary.

g. Additionally, they present the photographs and / or videos of the experimental development.

h. Finally, request that students present a concept map on a poster where they integrate the acquired learning.

i. Additionally, it is suggested that the teacher request the students a written report and an oral seminar with visual support of PowerPoint type parcel that includes: the problem, objectives, hypotheses, description, and argumentation of the procedures used to determine and obtain the required physicochemical parameters, and that they present the solution of the problem, that generate their own conclusions and annex the bibliography used.

\subsection{Process evaluation}

After the PBL process, the student has acquired, through autonomous and cooperative learning, the necessary knowledge and has developed and trained the competences foreseen in the program of the subject thanks to a deep reflection and an active construction of the learning. Then, the evaluation can be done in various ways quantitatively, qualitatively and opinion polls. It is important to mention that based on the taxonomy of Barrow (1986), as well as the proposal in this material based on the taxonomy of Bloom (Marzano \& Kendall, 2007), the evaluation can take the following options:

Other's methods of PBL in which students must put into practice everything they have learned A written exam, considering the different levels of Bloom's taxonomy, such as the recognition, understanding, for the contents studied, but that implies that the student coherently organizes his knowledge.

Peer review (co-evaluation). The student, during his learning process, has worked with his classmates cooperatively. Therefore, knowing the opinion of colleagues is also interesting. The aspects that can be asked can be cooperative environment within the group, effective distribution of tasks, fulfillment of expectations as a group, etc.

Self-assessment: The student has carried out an autonomous learning process. Therefore, no one better than himself knows everything he has learned and everything he has striven for. Some aspects can be established for the student to self-evaluate learning achieved, time invested, process followed, etc.

Satisfaction Survey: In Problem-Based Learning, it is important to know the student's point of view regarding the satisfaction of the methodology applied through a questionnaire with a Likert scale. It can be determined if PBL motivates the resolution of the problem, if it facilitates the understanding of theoretical concepts, if it facilitates teamwork, if they consider that they acquire a structuring of knowledge for use in chemical contexts, if it promotes a development of an effective chemical reasoning process, if it promotes a development of self-directed learning skills, if it generates greater motivation to learn, and so on. 


\section{Conclusions}

The term problem-based learning (PBL) should be considered a genus for which there are many species and subspecies. Each is aimed at different goals to varying degrees. In each method of the PBL, different levels of Barrow's taxonomy can be reached for use in chemical contexts, and achieve an effective process of chemical reasoning such as the development of self-directed learning skills and motivation to learn In this taxonomy we can evaluate with a written exam, with a peer review (co-evaluation), a self-assessment or satisfaction survey, however, by proposing a relationship of Barrow's taxonomy with Bloom's taxonomy, this will allow the teacher to know in a less qualitative and personal interpretation way the level of structuring of the knowledge of students for use in chemical contexts.

Any teacher who wishes to employ PBL must decide on desired educational goals and then select the method that best suits them.

\section{ACKNOWLEDGEMENT}

PAPIME PE212118: Aprendizaje Basado en problemas: Fisicoquímica Farmacéutica DGAPA UNAM

PAPIME: PE: 101721 Aprendizaje Basado en Problemas en Línea. Fisicoquímica DGAPA UNAM

Paola Vianey Martínez Vega

Maricruz Castro Trejo

Licenciatura en Diseño y Comunicación Visual FES Cuautitlán UNAM

\section{REFERENCES}

[1] Amol C. Adámate, Sandeep U. Mane (2020) PBL based Teaching-learning Strategy for Inculcating Research Aptitude in CS/IT Students. Journal of Engineering Education Transformations, Volume 33, January 2020, Special issue, eISSN 2394-1707 585

[2] Barrows, H. S. \& Tamblyn, R. M. (1980) 1 Problem-Based Learning: An Approach to Medical Education. Springer Publishing Company.

[3] Barrows, H. S. (1986) A taxonomy of problem-based learning methods. Medical Education, 20 (6), 481-486. https://doi.org/10.1111/j.1365-2923.1986.tb01386.x.

[4] Barrows, H. S. (1996). Problem-based learning in medicine and beyond: A brief overview. New Directions for Teaching and Learning, 1996 (68), 3-12. https://doi.org/10.1002/t1.37219966804

[5] Boyce, M. C., \& Singh, K. (2008). Student Learning and Evaluation in Analytical Chemistry Using a Problem-Oriented Approach and Portfolio Assessment. Journal of Chemical Education, 85(12), 1633.

[6] Correa, M. E. y Castro, F. \& Lira, H. (2002). Hacia una conceptualización de la metacognición y sus ámbitos de desarrollo. Horizontes Educacionales, (7), 58-63.

[7] Díaz Barriga, F. \& Hernández, G. (2002), Estrategias docentes para un aprendizaje significativo: una interpretación constructivista, México, Mc Graw-Hill.

[8] Fernández, L. F. \& Aguado, M. I. (2017) Aprendizaje basado en problemas como complemento de la enseñanza tradicional en Fisicoquímica. Educación Química, 28 (3), 154-162.

[9] Hicks, R. W., \& Bevsek, H. M. (2011). Utilizing Problem-Based Learning in Qualitative Analysis Lab Experiments. Journal of Chemical Education, 89(2), 254-257. doi:10.1021/ed1001202.

[10] Irazoque, G. (2005) Más problemas ¿Para qué? Educación Química, 16 (2) 279-283.

[11] Izquierdo, M. (2005). ¿Para qué se inventaron los problemas de química? Educación Química, 16 (2) 246-259.

[12] Kayala, M. A., Azencott, C.-A., Chen, J. H., \& Baldi, P. (2011). Learning to Predict Chemical Reactions. Journal of Chemical Information and Modeling, 51(9), 2209-2222.

[13] Kyung-Hee Choi (2018): Eco-tech fashion project: collaborative design process using problem-based learning, International Journal of Fashion Design, Technology and Education, DOI: $10.1080 / 17543266.2018 .1516808$ 
[14] Martínez-Torregrosa, J.; Gil Pérez, D.; Becerra-Labra, C. y Guisasola, J. ¿Podemos mejorar la enseñanza de la resolución de problemas de "lápiz y papel” en las aulas de Física y Química?, Educación Química, 16 (2), 230-245.

[15] Marzano, R., \& Kendall, J. (2007). The new taxonomy of educational objectives (2nd ed.) Thousand Oaks, CA: Corwin Press.

[16] Matus, Olga, Sylvia Palacios, Alejandro Soto y Eduardo Fasce (2005). Utilización del aprendizaje basado en problemas en la enseñanza de informática básica. Revista Médica de Chile, 21, 15-21.

[17] Obaya Valdivia, Carlos Montaño Osornio, Yolanda Marina Vargas-Rodríguez (2021) PBL with the Application of Multiple and Nonlinear Linear Regression in Chemical Kinetics and Catalysis American Journal of Educational Research, 2021, Vol. 9, No. 1, 31-37 Available online at Published by Science and Education Publishing DOI:10.12691/education-9-1-4

[18] Obaya, A., Vargas-Rodríguez, G. I., Lima-Vargas, A. E. \& Vargas-Rodríguez, Y. M.(2018) Aprendizaje basado en problemas: ¿En qué tiempo se descompone la leche pasteurizada a temperatura ambiente? Educación Química, 29(1), 99-109. http://dx.doi.org/10.22201/fq.18708404e.2018.1.63701.

[19] Obaya, A.; Vargas, Y. M. \& Delgadillo, G. (2011). Aspectos relevantes de la educación basada en competencias para la formación profesional. Educación Química, 22 (1), 63-68.

[20] Ramos-Mejía, A. \& Palacios-Alquisira, J. (2007). Elementos del aprendizaje experimental basado en un problema para la enseñanza superior en Fisicoquímica. Educación Química, 18 (3) 214-221.

[21] Salari, M., Roozbehi, A., Zarifi, A., \& Tarmizi, R. A. (2018). Pure PBL, hybrid PBL and lecturing: Which one is more effective in developing cognitive skills of undergraduate students in pediatric nursing course. BMC Medical Education, 18(1), 195. https:// doi.org/10.1186/s12909-018-1305-0

[22] Servant-Miklosa, V. F.C. (2019) Fifty Years on: A Retrospective on the World's First Problem-based Learning Programme at McMaster University Medical School. Health Professions Education, 5, 3 12.

[23] Shultz, G. V., \& Li, Y. (2015). Student Development of Information Literacy Skills during ProblemBased Organic Chemistry Laboratory Experiments. Journal of Chemical Education, 93(3), 413-422.

[24] Sola, C., M. Porres, R. Gentil, L. Epstein, G. Lapuente, S. Limón, F. Sierra, J. Neri, M. McCoy, J.R. Álvarez, I. Delgado \& F. Illescas (eds.) (2006). Aprendizaje basado en problemas. De la teoría a la práctica. México: Trillas

[25] Stentoft, D. (2019). Problem-based projects in medical education: extending PBL practices and broadening learning perspectives. Advances in health sciences education theory and practice, 24(5), 959-969. https://doi.org/10.1007/s10459-019-09917-1

[26] Torp, L. \& Sage, S. (1999). Aprendizaje Basado en Problemas: desde el jardín de infantes hasta el final de la escuela secundaria. Buenos Aires: Amorrortu.

[27] Vargas-Rodríguez, Y. M., Obaya, A. E., Montaño-Osorio, C., Lima-Vargas, A. E., Pacheco-Ortín, S. M., Vargas-Rodríguez, G. I. (2020) Online Applied Problem-Based Learning to determine the shelf life (expiration date) of an on-site solution of refrigerated drug. International Journal of Educational Technology and Learning, 9 (1)10-18, 2020. DOI: 10.20448/2003.91.10.18.

[28] Vargas-Rodríguez, Y. M., Obaya-Valdivia A. E., Vargas-Rodríguez, G.I., Villalobos-García, R. and Lima-Vargas, A. E. (2021) ITC: PBL Online Pharmaceutical Physical Chemistry Update Experiences of Teachers Baby Boomers and Millennials. International Journal of Development Research, 11(3), 45583-45589.

[29] Villalobos, D. Áviña, P. \& Olivales, O. (2016). Aprendizaje basado en problemas en química y el pensamiento crítico en secundaria. Revista Mexicana de Investigación Educativa, 21(69), 557-581.

[30] Williams, D. (2016). Creating an assessment and feedback strategy for problem-based learning chemistry. Student Engagement in Higher Education Journal, 1 (1) 1-13.

[31] Winschel, G. A., Everett, R. K., Coppola, B. P., Shultz, G. V., \& Lonn, S. (2015). Using Jigsaw-Style Spectroscopy Problem-Solving to Elucidate Molecular Structure through Online Cooperative Learning. Journal of Chemical Education, 92(7), 1188-1193. 
International Journal of Education (IJE) Vol.9, No.4, December 2021 